\title{
El periplo del objeto mitológico: itinerarios simbólicos del arte prehispánico entre los siglos XVI y XX
}

María Alba Bovisio ${ }^{1}$

Artículo científico

Material original autorizado para su primera publicación en el Journal de Ciencias Sociales, Revista Académica de la Facultad de Ciencias Sociales de la Universidad de Palermo.

Recibido: 8-10-2013

Aceptado: 9-1-2014

"Los objetos no nos envían las imágenes reales sino las deseadas"

Jean Baudrillard

\section{Resumen:}

El presente texto discute la "identidad" que los objetos de arte prehispánico adquirieron desde el siglo XVI hasta mediados del siglo XX de acuerdo a los circuitos que recorrieron y los sujetos que los coleccionaron, miraron y pensaron. Itinerarios concretos: del contexto ritual al gabinete de curiosidades, del gabinete al museo arqueológico, del museo arqueológico a la muestra en espacios de arte. Itinerario que expresa las significaciones que el moderno Occidente les asignó en relación a sus propias necesidades, anhelos y carencias.

Palabras clave: arte prehispánico, gabinetes de curiosidades, museos arqueológicos, historiografía prehispánica.

\begin{abstract}
:
This text discusses the "identity" that pre-Hispanic art objects acquired from the sixteenth to the twentieth century according to the circuits that they traveled and the subjects that collected, regarded and looked at them. Specific itineraries: from the ritual context to the cabinet of curiosities, from the cabinet to the archaeological museum, from the archaeological museum to the art displays. These itineraries express the meanings that the modern West assigned to those objects in relation to their own needs, desires and lacks.
\end{abstract}

Keywords: pre-Hispanic art, cabinets of curiosities, collections, archaeological museums, preHispanic historiography.

\section{Introducción}

Los objetos, en la medida que existen en relación a los sujetos, adquieren significaciones y agencias según quienes los interpelan y a su vez son interpelados por aquellos. En el presente texto nos interesa abordar la posibilidad de indagar en los objetos prehispánicos esas interpelaciones a partir del siglo XVI. En este itinerario simbólico habría tres paradigmas dominantes: durante la

\footnotetext{
${ }^{1}$ Profesora titular. Facultad de Ciencias Sociales. Universidad de Palermo. mariaalbab@yahoo.com.ar
} 
época colonial el de "curiosidad/maravilla/ídolo"; desde fines del siglo XVIII y durante el XIX el de "documento histórico-arqueológico", y en el siglo XX el de "arte primitivo".

La mayor parte de los trabajos que han abordado esta cuestión se concentran en las colecciones de arte prehispánico mexicano que fueron las que generaron el primer gran impacto en Europa $^{2}$, comenzando con los famosos objetos que en 1519 envió Cortés a Carlos V junto con la primera de sus Cartas. Estos regalos fueron exhibidos en los Países Bajos al año siguiente, ocasión en la que fueron admirados por Durero, quien dejó constancia de esta admiración en su Diario:

También vi las cosas que se han traído del Nuevo Mundo dorado: un sol de oro de una toesa de ancho y una luna de plata del mismo tamaño [...] todo tipo de cosas preciosas para diversidad de usos que es cosa tan hermosa de ver como prodigiosa. Todas tan costosas que puede considerarse en mas de cien mil gulden de valor. Yo no he visto nada en toda mi vida que haya alegrado tanto mi corazón, extraordinarias cosas de industria y me he maravillado del sutil ingenio de los hombres en tierras extrañas. Yo no soy capaz de expresar las cosas que he visto (Dürer, 1914 [1520], p.25).

En el momento inaugural de la relación de Europa con estas piezas (y con sus hacedores vivos y activos en ese momento) la valoración de las mismas como "arte" está presente tal como lo demuestra la elogiosa descripción que hace Bernal Díaz del Castillo acerca de los "artistas" mexicas:

...digamos de los grandes oficiales que tenía [Moctezuma] de cada oficio que entre ellos se usaban. Comencemos por lapidarios y plateros de oro y plata y todo vaciadizo, que en nuestra España los grandes plateros tiene que mirar en ello [...] Vamos adelante a los grandes oficiales de labrar y entalladores muy sublimados, que por lo que ahora hemos visto la obra que hacen, tendremos consideración en lo que entonces labraban; tres indios hay ahora en la ciudad de Méjico tan primísimos en su oficio de entalladores y pintores [...] que si fueran en el tiempo de aquel antiguo o afamado Apeles, o de Micael Angel o Berrugete, que son de nuestros tiempo, también les pusieran en el número de ellos (Bernal Díaz del Castillo, 1992 [1568], pp. 169-70).

El asombro y admiración están presentes en los juicios de Bernal Díaz y de Durero pero en el de este último el valor "estético" atribuido a las piezas se conjuga con el de "curiosidad", aquellos son objetos producidos por "hombres en tierras extrañas" y esto genera un plus ligado no tanto al

\footnotetext{
${ }^{2}$ Entre los siglos XVI a XVIII las piezas precolombinas que ingresaban a Europa eran en su mayoría mexicanas y de la zona maya, salvo algunas piezas tainas. Francisco de Xerez, secretario de Pizarro, en su Relación señala que entre 1533 y 1534 llegaron a Sevilla procedentes del Perú cuatro naves con "pesos de oro" y "marcos de plata" además de 38 vasos de oro, 48 de plata, 2 ollas grandes una de oro y otra de plata, y "un ídolo de oro del tamaño de un niño de cuatro años"; explica que "este tesoro fue descargado en el muelle y llevado a la casa de la contratación" y concluye en que "suma el oro de estas cuatro naos setecientos ocho mil quinientos ochenta. Es tanto un peso de oro como un castellano. Véndese comúnmente cada peso por 450 maravedíes y contando todo el oro que se registró en las cuatro naos, sin poner cuenta en las vasijas, suma ochocientos setenta y un mil maravedíes y la plata cuarenta y nueve mil marcos..." (de Xerez (2003 [pp.47-48). No sabemos cuál fue el destino del ídolo de oro puesto que no se ha hallado nada similar en ninguna colección europea, quizás fue fundido en Europa, y por otra parte, es probable que otros objetos peruanos hayan sido transformados en lingotes antes de zarpar para facilitar el transporte desde los Andes hasta los barcos anclados en el Atlántico y en el Golfo de México, al respecto el secretario de Pizarro, señala: "Lo sobredicho vino en barras y planchas y pedazos de oro y plata cerrados en cajas grandes" (ibídem). Al parecer la consideración del valor "artístico" de los objetos andinos de oro y plata quedó relegada frente a su valor mercantil.
} 
valor de lo "bello" sino del "prodigio". La otra variable en juego es el material: "mundo dorado", ese es el color con el que se identifica al Nuevo Mundo, que remite evidentemente a un valor mercantil. Justamente es este valor el que permite la coexistencia de estos juicios y del interés europeo por las colecciones de objetos maravillosos de aquellas lejanas tierras con la condena de los extirpadores de idolatrías. Ciertamente, tal como lo consignan las fuentes etnohistóricas, la mayor parte de los ídolos destruidos eran de piedra; en este sentido coincidimos con Gruzinski cuando señala que: “...el ídolo siempre que tenga valor mercantil deja de ser una representación demoníaca para convertirse en objeto de valor" (Gruzinski, 1994, p. 51).

Vemos entonces que los objetos prehispánicos condensaron en un principio varios sentidos: por un lado objetos idolátricos, "cosas malas donde se mete el diablo", por otro, el de "curiosidades" de aquellas tierras extrañas, y por otro, el de objetos bellos y "maravillosos", donde lo que más se destaca en los juicios son las referencias a los materiales, sobretodo a los metales preciosos y al arte plumario, y a las habilidades plásticas de sus hacedores, por ejemplo, el "naturalismo" de las esculturas aztecas de animales, que destaca Cortés: "tenían contrahechas muy al natural todas las cosas criadas así en la tierra como en el mar" (Cortés,1963, p.70).

El valor mercantil y no el estético será el que mueva al robo y saqueo de tumbas y centros ceremoniales desde la Conquista hasta nuestros días. El valor de "curiosidad" será el que ubique a estos objetos en el concierto de todo lo que exprese metonímicamente al Nuevo Mundo como anómalo y extraño, extraordinario y exótico: hombres, plantas, animales y cosas ("curiosidades naturales" y curiosidades artificiales"). Sabemos que Colón "regaló" a los Reyes Católicos ejemplares de indios caribes. Báez y Mason destacan que en su diario menciona que se llevó 31 de los cuales no sabemos cuántos llegaron vivos a España (Báez y Mason, 2006, p. 19). En el mismo sentido Cortés envió objetos de oro y plata mesoamericanos al rey Carlos $\mathrm{V}$, puesto que al aprecio mercantil se sumaba el de la curiosidad, valor que compartían objetos y personas amerindias. El hermano menor del rey, Ferdinando I, quien puede considerarse el primer coleccionista de arte prehispánico (cuya labor fue continuada por sus hijos), atesoró en su gabinete numerosas piezas mexicanas de la colección familiar de los Habsburgo.

Shelton sostiene que:

\begin{abstract}
A large part of the justification for collections in the Renaissance was borrowed from the medieval scholasticism, its ideas concerning the innate meaning of things and the nature of revelation, and its vision of the relationship between the microcosm and the macrocosm (Shelton, 1994, p.181).
\end{abstract}

De modo que, poseer "la curiosidad", que tenía una relación especial con la totalidad, implicaba para el hombre del Renacimiento alcanzar simbólicamente el control de esa totalidad (todos los mundos conocidos). Para Antonio Giganti, como para otros clérigos coleccionistas, la colección que organiza en su Museo Enciclopédico es una gran metáfora del mundo que da cuenta de un orden Divino. Para los científicos, como el naturalista Ulises Aldrovandi, quien adquirió máscaras incrustadas en turquesa, cuchillos de obsidiana y figuras de oro aztecas y mixtecas para su Museo de Historia Natural y Etnología, las colecciones enciclopédicas son también metáforas pero de un orden natural y humano que debe estudiarse, sobre todo, en aras de que Europa conozca el mundo que 
ha conquistado. Según Shelton, la perfección del modelo de secularización del ideal enciclopédico se dará con Francisco I, Duque de Toscana hacia 1574, quien abrió su colección al público en el Palacio de los Uffizi en Florencia para gloria de la familia Medici y legitimación de su posición política (ibídem, p.186).

Ya sea como metáfora de un orden divino o natural, el ideal enciclopédico que sustentó esas colecciones expresaba una imagen de mundo construida en relación a la propia imagen que Europa elaboraba de sí misma, porque como afirma Baudrillard: "La posesión [...] es siempre la del objeto abstraído de su función y vuelto relativo al sujeto", (Baudrillard, 1999, p.97). De ahí que la valoración de los objetos prehispánicos, expresión metonímica de sus productores y de su espacio de pertenencia, oscilara entre el imaginario de la América paradisíaca habitada por seres inocentes (equiparables a los niños), en oposición a la corrupta Europa, y el de la América salvaje habitada por caníbales e idólatras, que debía ser redimida por el civilizado y cristiano Occidente.

A partir del último tercio del siglo XVIII se da un giro en el modo en que se interpela a estos objetos, Alexander von Humboldt es uno de los personajes que marca un punto de inflexión y el pasaje del paradigma de la "curiosidad" o "maravilla" al del "documento histórico-arqueológico". En el Atlas pintoresco que acompaña las Vistas de la cordillera y monumentos de los antiguos pueblos de América presentó una docena de planchas con imágenes sobre antigüedades y monumentos prehispánicos rescatados no por su valor estético sino histórico:

Los monumentos de pueblos que no han alcanzado un alto grado de cultura intelectual, o los cuales, ya sea por causas políticas y religiosas, o a causa de la naturaleza de su organización eran poco receptivos para la belleza de las formas, solo merecen atención como monumentos históricos (Humboldt et Bonpland, 1971 [1810], p.1).

A partir de este momento el objeto adquiere una existencia en un sistema, es decir, puede ser clasificado por su pertenencia a un tiempo y a un espacio determinado, cambio signado por el progresivo desarrollo de la Arqueología y la naciente Etnología en el Viejo Continente, sumado al auge de las Ciencias Naturales.

La reivindicación de la importancia de conocer los monumentos y la arquitectura de la América prehispánica implicó sumar a los objetos coleccionados en gabinetes y museos europeos, las imágenes (grabados primero, fotografías después) de aquello que no se podía trasladar ${ }^{3}$. Los artistas acompañan tanto a naturalistas como a arqueólogos generando estas nuevas colecciones. Ahora no solo se recolectan los objetos en su formato material sino icónico. Tal es el caso de los famosos grabados del inglés Frederick Catherwood que partió con John Lloyd Stphens a América Central registrando las ruinas de las ciudades mayas exploradas (Copán, Palenque, Quiriguá). Estas imágenes acompañaron el texto de gran difusión en Europa Incidents of Travel in Central America, Chiapas and Yucatán publicado en Londres en 1841. Las esculturas monumentales aztecas descubiertas en 1790 en la Plaza Mayor de México, el "Calendario", la "Piedra de Tizoc y la

\footnotetext{
${ }^{3}$ El afán de acopio, como es sabido, fue inconmensurable de modo que el límite de lo trasladable aplica parcialmente a los monumentos y la arquitectura, puesto que ante la imposibilidad de trasladar edificios enteros (imposibilidad relativa si pensamos en lo que los ingleses se llevaron de Egipto y Grecia) se optó por llevarse pedazos de arquitectura, por ejemplo, los magníficos relieves de los dinteles de las ciudad de Yaxchilán (Chiapas, México) que representa una de las expresiones más exquisitas y complejas de la escultura maya fueron llevadas a Londres a fines del siglo XIX sin mayor problema y hoy forman parte de los Tesoros del British Museum. Estos dinteles (identificados con los números 24, 25, 17 y 15) formaban parte de las puertas de edificios ceremoniales.
} 
Coatlicue", fueron registrados en grabados, que circularon por Europa a través de diversas crónicas de viajes como la de Carl Nebel, Viaje pintoresco y arqueológico por la parte más interesante de México, publicado en París en 1836.

Este nuevo modo de apropiación y colección, la del registro icónico, se da en el mismo momento en que muchos de los objetos colectados en los siglos anteriores son depositados en Ios noveles museos del siglo XIX: British Museum de Londres; Harvard's Peabody; Ethnologisches Museum de Berlín; Völkerkunde de Viena; Musée du Trocadero de París; Museum of Natural History de Nueva York. A lo largo del siglo XIX la progresiva instauración de un esquema evolucionista para comprender la otredad sustenta la posibilidad de pensar a las civilizaciones de América plausibles de equiparase con otras "grandes civilizaciones de la antigüedad"; la existencia de escritura jeroglífica en Mesoamérica, por ejemplo, alentó la comparación con el Antiguo Egipto. En muchas colecciones los objetos prehispánicos coexisten con objetos egipcios o chinos e incluso se los confunde: en la catalogación temprana del British Museum se identifica como egipcia una máscara incrustada en turquesa de origen mexica y una escultura mixteca de piedra se describe como "una cabeza egipcia del Sol" (Shelton, op. cit., p.203).

Las colecciones privadas de los siglos XVI y XVII en muchos casos se dispersaron, ya que gran parte de estos objetos fueron destinados a regalos de reyes y nobles ${ }^{4}$. Sólo desde fines del siglo XVIII en adelante se instauró una política sistemática de rescate y preservación de esos objetos; la organización de las colecciones en museos etnográficos y de historia natural era parte de la empresa colonial europea en torno al progreso; como así también lo fueron las expediciones financiadas por el Estado o por capitales privados en aras de ampliar el conocimiento científico sobre sus colonias recolectando y clasificando, material e "icónicamente", especímenes naturales y artificiales, monumentos y topografías ${ }^{5}$.

Pese a la nueva voluntad cientificista, pervivió la concepción de los objetos como artefactos que pueden coexistir con elementos de la naturaleza para expresar a los pueblos en peculiares metonimias $^{6}$. Por otro lado, la identificación con las antiguas civilizaciones fundada en un esquema evolucionista contradice la voluntad taxonómica, propia de las ciencias naturales, de ubicar a los objetos y seres de esas culturas como "especímenes". William Bullock, inglés coleccionista de curiosidades etnográficas y naturales organizó la primera exposición precolombina en Londres con piezas prehispánicas traídas de México durante un viaje de 6 meses en 1822. A las piezas originales se le sumaban réplicas de las tres famosas esculturas monumentales "descubiertas" en el siglo anterior, el "Calendario azteca", la "Piedra de Tizoc y la Coatlicue", y especímenes botánicos y zoológicos, exhibidos en una sala con columnas egipcias que mandó construir especialmente (Braun, 1993, p.30).

La primera mitad del siglo XX es el momento en que los objetos prehispánicos adquieren un nuevo sentido para la mirada europea, impregnada del primitivismo que caracterizó el desarrollo

\footnotetext{
${ }^{4}$ Por ejemplo, de la gran cantidad de objetos que recibió Carlos V entre 1519 y 1530, regaló 78 piezas mexicanas a su tía Margarita de Austria y esta a su vez, obsequió 14 de ellas al Duque de Lorena y 6 al príncipe de Mayence (Alcina Franch, 1995, p.31).

${ }^{5}$ Marta Penhos ha analizado las representaciones icónicas y escritas generadas por la entrada en el Gran Chaco del comandante Matorras, los viajes de Félix de Azara y la Expedición Malaspina poniendo en relación los "modos de visualidad" europea con las prácticas de acopio de conocimiento sobre el territorio sudamericano y los mecanismos de dominación durante el siglo XVIII (Penhos 2005).

${ }^{6}$ De hecho, también el límite entre el objeto de arte exótico y la curiosidad siguió siendo difuso, tal como evidencia la existencia en Berlín a principios del siglo XIX de una "Galería de Arte y Rarezas", que acogió la colección de objetos prehispánicos llevada desde México a Europa por Alexander von Humboldt.
} 
del Arte de vanguardia y la Etnología, se instaura, entonces, una nueva dimensión, la estética, que funcionará más allá de su valor religioso, histórico, mercantil o exótico. El contacto con el arte de las colonias de África y Oceanía favoreció el desarrollo del "gusto" por el "arte negro"7 e incentivó la búsqueda de cubistas, fauvistas, dadas, expresionistas, etc. de nuevas formas artísticas ajenas al legado occidental decimonónico. Al interés de los artistas se sumaba el de la Etnología; corresponde fundamentalmente al alemán Franz Boas la invención de la concepto "Arte Primitivo" en términos antropológicos, a partir de la publicación, en 1927, de su texto Primitive Art donde, al proponerse: “... dar una descripción analítica de los rasgos fundamentales del arte primitivo", plantea el estudio de este no como análisis de casos, sino como categoría (Boas, 1947, 7).

Si bien hay matices diferenciales en las miradas de los distintos movimientos de vanguardia y en la propuesta de la naciente Etnología lo que predomina es la idea de que lo que se rescata de estos objetos es su no-occidentalismo, su anti-ilusionismo, su "no ser", lo que fue el arte desde el Renacimiento en adelante. Aquí acontece una elocuente paradoja: la reivindicación "progresista" por parte de las vanguardias europeas del "arte primitivo" termina articulando la misma "operación colonialista" de los siglos anteriores: objetos precolombinos coexisten identificados y emparentados con objetos africanos, chinos, egipcios, etc. Parecerían no ser dignos de una historia e identidad propias, sino que esta se define en relación con los anhelos renovadores de la representación plástica occidental (Bovisio 1999). Como bien señala Paternosto: "La historia de la llegada de los objetos de colonias europeas y su impacto en las vanguardias artísticas de las primeras décadas del siglo XX ya pertenece al discurso dominante..." (Paternosto, 2001, p. 18).

La célebre exposición en el Pabellón Marsan del Museo del Louvre en junio de 1928, Les Arts Anciens de l'Amérique, marca un hito por varias razones, por un lado es la primera vez que se exhiben piezas prehispánicas presentadas en una muestra de arte, aunque claro está, de "Arte primitivo". Esta muestra involucró la participación de antropólogos, escritores y artistas (algunos de ellos vinculados a la antropología argentina y la plástica latinoamericana). La exposición fue montada por el etnólogo Alfred Metraux, quien a fines de ese mismo año se instaló en la Argentina, donde permaneció hasta 1934, y fundó el Instituto de Etnología de Tucumán, y por Georges Henri Rivière, estudiante de música, apasionado por el jazz, que llegó a ser museólogo etnográfico (Clifford, 1995, p.160). El catálogo, publicado por la editorial G. Van Oest, incluyó textos de Raoul d' Harcourt, George Bataille, Métraux y Paul Rivet. Este último, director del Museo del Trocadero, quien contrató a Rivière por el éxito de la muestra para que reorganizara este museo, lo que daría origen al Museo del Hombre.

Para la misma época la editorial G. Van Oest publica la colección Ars Americana y como parte de esta aparece, póstumamente, en 1931, la obra del arqueólogo argentino Salvador Debenedetti, L'Ancienne Civilisation des Barreales, sobre la colección arqueológica de Muñiz Barreto, prologado por Paul Rivet. Esta es una de las más tempranas noticias del arte argentino prehispánico en Europa y evidencia la valorización de las cualidades plásticas y estéticas del arte prehispánico. Debenedetti escribe el texto consciente de esta mirada, que en el prólogo Rivet destaca: "M.Benjamin Muniz Barreto [...] avait ainsi constitué la plus belle collection archéologique des hautes plateaux argentins qui soit au monde" (Debenedetti 1931, p.11). El autor señala los dos valores de esta colección

\footnotetext{
${ }^{7}$ Categoría construida por el discurso etnográfico de fines del siglo XIX que identificaba en un mismo registro tanto el arte de África con el de Oceanía (Bovisio 1999).
} 
"científico y artístico": estas piezas, procedentes principalmente de las excavaciones, financiadas por Muniz Barreto y realizadas por el ingeniero Vladimir Weiser entre 1925 y 1929, de cementerios en los valles catamarqueños de Ciénaga y Hualfín, permiten apreciar una "fase del desarrollo del arte prehispánico". Luego dedica varias páginas a describir el medio ambiente, los cambios climáticos, el proceso de despoblamiento de esos valles, etc., para continuar con la descripción de las tumbas y concluir en que estos yacimientos evidencian una "civilización avanzada". Siguiendo el esquema evolucionista imperante considera que es por el "grado de evolución" de sus hacedores que estas obras pertenecen a "antiguas civilizaciones" y reivindica para ellas un lugar destacado en la arqueología y la historia del arte americano (op. cit., p. 13).

La descripción de las piezas va acompañada de juicios de valor: pondera a los ceramistas por la habilidad para seleccionar la mejor arcilla, modelarla con "prodigiosa maestría" (una vez más el prodigio) decorarla de "una manera artística y segura"; señala también la perfección de la cocción y de las formas, la regularidad de la técnica, la precisión en la ejecución, solo comparables a las de las cerámicas de la cultura $\mathrm{Nazca}^{8}$ (op. cit., p. 14). A los valores técnicos suma los plásticos: la evidencia de un canon riguroso y un gran sentido de la composición. De los vasos de piedra ciénaga elogia la serenidad de expresión y la firmeza del diseño de los zoomorfos esculpidos. Pero, más allá o más acá de todos los elogios, en el discurso de Debenedetti, en sintonía con el discurso del arte y la etnología de los años 20 y 30, queda claro que el lugar que le cabe a estas "bellas piezas" en el sistema de los artefactos culturales es el de "arte primitivo" y "artes decorativas". A propósito de la representación del hombre en estas cerámicas señala que tiene un lugar muy importante, "como en todas las cerámicas decoradas de carácter primitivo" (op. cit., p.19). En la interpretación de las características plásticas sostiene que se da una evolución de un arte naturalista a uno esquemático, donde el "artista primitivo" no pierde de vista los rasgos fundamentales de los motivos representados "basado siempre en la realidad del medio" y les atribuye a estos valor de símbolos. Vemos cómo la idea de síntesis y esquematización de la naturaleza en aras de construir símbolos, paradigma que se aplicaba a las artes ornamentales de las "antiguas civilizaciones" se aplica aquí al arte argentino prehispánico. Por otro lado, señala que estos objetos portadores de cualidades estéticas, deben entenderse en relación con sus funciones ceremoniales y rituales, pero no ahonda en este aspecto porque el hincapié está en la valoración artística de la colección, como si ambas dimensiones fueran inconciliables en un único discurso.

El texto de Debenedetti se publica en el momento en que se está dando el pasaje del museo Trocadero al nuevo Museo del Hombre. Si en el primero la acumulación de objetos premodernos ("arte primitivo") sin contextualización científica coherente alentaba su apreciación atemporal como "obras de arte", en el Museo del Hombre, concebido a partir del humanismo etnográfico, devendrán "artefactos culturales". El pasaje de un modelo de museo a otro implicó la clara diferenciación del paradigma etnográfico y el artístico. Paul Rivet, su director, estableció una orden formal contra el tratamiento estético de los artefactos, los objetos debían presentarse en contextos reconstruidos e interpretados y clasificados según su ubicación espacio-temporal y su función (Clifford op. cit., p. 186). El arte prehispánico quedó definitiva y anacrónicamente integrado al espacio de las culturas etnográficas, identificándose el "arte" de imperios como el inca y azteca con el de organizaciones

\footnotetext{
${ }^{8}$ Cultura desarrollada en la costa sur del Perú entre los siglos I-VIII.
} 
tribales de África y Oceanía9. El periplo de la colección prehispánica de Nelson Rockefeller es elocuente al respecto: en la década del '30 dona parte de esta colección al Metropolitan de Nueva York, sin embargo, el museo no considera pertinente incorporar esas piezas a su patrimonio y las envía al de Historia Natural. Recién en 1982 el Met los recibe pero en la sala "Artes de África, Oceanía y América", exhibe esta colección pero justamente junto a piezas etnográficas.

Volviendo a la exposición Les Arts Anciens de l'Amérique, esta fue vista por el artista uruguayo Joaquín Torres García, residente en Europa desde 1891, imbuido del espíritu vanguardista europeo atravesado por su adscripción a la filosofía neoplatónica y pitagórica (al igual que otros vanguardistas europeos y latinoamericanos, un amplio arco de personalidades desde Mondrian, Kandisnky, Itten hasta Ricardo Rojas y José Vasconcelos entre otros). Torres ve esa exposición el mismo año en que, como él mismo cuenta en su autobiografía, en su obra "se inicia otra cosa". El sentido arquitectural constructivo de su pintura. Se produce una disociación entre dibujo y color que quedan como cosas separadas pero en el tono, en el color y en la línea, no en lo representativo. "Estos elementos ahora se representan a sí mismos” (Torres García 2000, p.142). Es decir, Torres está arribando a su teoría y práctica del Universalismo Constructivo, que tendrá como fuente, además del arte clásico, las "artes negras" y las antiguas, al arte precolombino ${ }^{10}$. A partir de 1930 va a "experimentar" sistemáticamente con imágenes tomadas del arte prehispánico, obras aztecas, mayas, incas y preincaicas, y de los indígenas de Norteamérica, considerando que estas culturas pueden ubicarse al igual que las mediterráneas entre las antiguas civilizaciones que supieron aprehender en la relación con la naturaleza una verdad trascendente:

El hombre que nos antecedió supo distinguir perfectamente el espíritu que moraba en cada cosa y lo configuró en un signo. Y tal signo, para él fue un talismán. Su vista penetró más profundamente en la naturaleza que no la del hombre de hoy puesto que llegó a tal intuición: trascendió la materia. Todo fue espíritu para aquel hombre (y estuvo en lo cierto) el fuego, los vientos y el trueno, cualquier bicho o piedra...todo en su panteísta concepción universal (Torres García 1991, p.134).

La regla de oro era para Torres García "el eslabón que nos une a través de los siglos" y que permite alcanzar la meta de traducir ideas trascendentes a símbolos geométricos. Excede las posibilidades de este texto ahondar en la cuestión del "primitivismo" en Torres García, pero me interesa señalar que su perspectiva a diferencia de la de Debenedetti y los antropólogos del Museo del Hombre, integra en una unidad universalista los valores plásticos y mágico-rituales del arte. Respecto a su valoración del arte prehispánico, nos dice Mari Carmen Ramírez:

Lo que Torres García definió como el orden abstracto o universal no solo sirvió para legitimar la cultura prehispánica en el contexto de las civilizaciones del mundo, sino

\footnotetext{
${ }^{9}$ Esta concepción es consolidada por la etnología de Lévi-Strauss quien sostiene la dicotomía sociedad moderna, la occidental contemporánea vs. sociedades primitivas, categoría que incluye tanto a grupos etnográficos como a culturas del pasado premoderno, aunque establece salvedades respecto al México precolombino por la existencia de escritura que es el parámetro que para él define que una sociedad sea "primitiva" o no, tal como sostiene largamente en las conversaciones con Georges Charbonier que publica bajo el título Arte, lenguaje y etnología (Lévi-Strauss 1979 [1968]).

${ }^{10}$ El hijo mayor de Torres, Augusto, trabajaba en el museo del Trocadero y frecuentemente lo visitaban para admirar las colecciones de "arte primitivo".
} 
que situó su contribución artística al mismo nivel que la de las civilizaciones clásicas de la Antigüedad. El principio de la universalidad en la forma abstracta que vinculaba la contribución artística de los incas a la de los egipcios o la de los griegos arcaicos implicaba el derecho de los latinoamericanos no solo a participar del legado de las civilizaciones universales sino también a utilizar las convenciones de esas culturas en su arte (Ramírez, 1991, p.121).

Al instalarse en Montevideo en 1934 (después de 43 años de vida y desarrollo profesional en Europa), con la intención de fundar una "Escuela del Sur", su interés por el arte prehispánico andino se acentúa, en particular por el arte incaico que "encajaba" mucho mejor que otras expresiones en su teoría del universalismo constructivo: "la cultura inca [...] en su sencilla unidad [...] puede utilizarse como el modelo más conseguido" (Torres García 1939, p.3).

La elección del arte incaico como "el modelo más conseguido" será retomada por uno de los artistas argentinos vinculados con el legado de Torres García, que se destaca porque también él articula una riquísima producción plástica con una no menos rica producción teórica, César Paternosto. Este artista argentino, residente desde hace más de 30 años en Nueva York, encara a partir de los años 60, a la luz de la abstracción geométrica y el minimalismo, la búsqueda de una identidad fundada en los valores ancestrales de la cultura latinoamericana, valores que la conectan con una dimensión humana universal. Rescata el arte precolombino como "...arte abstracto que florece gracias a los parangones simbólico-estructurales de las artes aborígenes, es decir, las únicas artes originales del hemisferio, que en sus cualidades de equilibrio, proporción, ritmo, simetría expresa un orden cósmico" (Paternosto,1989, p.25).

Ahora bien, si en el caso de la concepción etnográfica el arte prehispánico permanece en el ámbito anacrónico de las culturas etnográficas, en los rescates de Torres y Paternosto (ambos complejos y dignos de discutirse extensamente), me permito sugerir que queda en el espacio metafísico de las "antiguas civilizaciones universales". En un caso se le pide al objeto prehispánico, más allá de sus cualidades artísticas o por ellas mismas que remita a la otredad etnográfica, en otro, esas cualidades lo remiten a la antigüedad originaria. El juicio de Cecilia Buzio de Torres, artista del taller de Torres, es elocuente al respecto: "Torres logró sintetizar el espíritu hermético e intemporal del arte peruano y el lenguaje geométrico propio del arte moderno" (Buzio de Torres 1991, p.23); el verdadero espíritu del arte andino prehispánico es "atemporal", la adscripción de este al universalismo constructivo lo ubica fuera de la historia ya que su verdad está más allá del tiempo.

El objeto prehispánico, objeto con múltiples existencias, diverso y complejo, cuyo sentido original se perdió en el momento mismo en que se arrancó de su contexto y función, en su largo periplo, de América a Europa y de Europa a América, del siglo XVI al siglo XX, adquirió diversos sentidos como signo polivalente que fue y es, pero puedo aventurar una hipótesis: tuvo un sentido subyacente permanente, el de objeto mitológico, carácter ligado al de su extrañeza y antigüedad. El Occidente moderno parecería demandar en la construcción de los sistemas de objetos que posee (recolecta y colecciona) objetos excéntricos, espacial y/o temporalmente, es decir, que remiten siempre al pasado, ya sea por antiguos o por etnográficos, ya que en su "premodernidad" aunque sean coetáneos a los ojos de Occidente corresponden a etapas previas a su "evolución". Inscriptos en un pasado lejano, perdida su función original, se constituyen en objetos mitológicos existentes en 
un tiempo consumado, perfecto, el tiempo originario.

Incluso en el momento de la conquista en el en que esos objetos no eran arqueológicos sino etnográficos, es decir, eran "usados" por los pueblos indígenas como esculturas religiosas, parafernalia ritual, ofrendas funerarias, etc., momento en que sus hacedores estaban vivos y sus habilidades y talentos se disponían para las artes de la colonia (el arte de la evangelización), la extrañeza de la otredad, la fantasía exótica de la América salvaje y paradisíaca a la vez, los inscribía en el ese pasado originario.

"El objeto antiguo se nos da como mito de origen", afirma Baudrillard (op. cit., p.86). A mi juicio, el objeto prehispánico ha conservado hasta hoy ese carácter. Es ese mito el que se busca aprehender desde el gabinete de curiosidades de los reyes y nobles europeos de los siglos XVI y XVII hasta las apropiaciones artísticas latinoamericanas que intentan construir mitos identitarios, pasando por las reivindicaciones de las vanguardias primitivistas y la etnología ${ }^{11}$.

Refiriéndose a la exposición Primitivismo en el Arte del Siglo XX realizada en el MOMA a mediados de los '80, Clifford señala que "el catálogo logra demostrar no tanto una afinidad esencial entre lo tribal y lo moderno o siquiera una actitud modernista coherente hacia lo primitivo como el deseo y el poder incansable del moderno Occidente de recolectar el mundo" (Clifford, op. cit., p.: 235). Afán coleccionista ligado, a mi juicio, tanto a la necesidad del recuperar a través de esos objetos el tiempo originario perdido, como a la de negarle a los hacedores de estos objetos una historia propia. La concepción establecida desde el siglo XIX en adelante de que el tratamiento de objetos premodernos como "arte" implica dejar de lado su contexto histórico original porque el arte es universal y atemporal, razón por la que a su vez la dimensión estética se excluye de la mirada científica de la etnología, da cuenta, no solo de la apropiación que la antropología hizo de estos objetos, sino de la necesidad de que solo puedan ser "estéticos" desde el paradigma etnográfico del "arte primitivo" o desde el paradigma de un esteticismo universalista. Quedó así excluida la posibilidad de pensar a estas manifestaciones plásticas como lenguajes particulares producidos en contexto socio-históricos concretos que pueden estudiarse desde una perspectiva histórica interdisciplinaria que no desatienda la especificidad de la dimensión estética existente en todo lenguaje plástico.

\section{Referencias bibliográficas}

Alcina Franch, J. (1995). Arqueólogos o Anticuarios, Barcelona: Ediciones del Serbal.

Báez, C. y Mason, P. (2006). Zoológicos humanos. Fotografías de fueguinos y mapuches en el Jardin de Acclimatation de Paris, siglo XIX, Santiago de Chile: Pehuén.

Baudrillard, J. (1999). El sistema de los objetos, México: Siglo XXI [1ª edición en francés 1968].

Boas, F. (1947). Arte Primitivo, México: F.C.E.

Bovisio, M. A. (1999). ¿Qué es esa cosa llamada «arte...primitivo»? Acerca del nacimiento de una categoría. En: Epílogos y prólogos para un fin de siglo. Buenos Aires: CAIA.

Bovisio, M.A. y Penhos, M. (2010). Arte indígena: categorías, prácticas, objetos. Córdoba: Encuentro Grupo editor/ Facultad de Humanidades.

\footnotetext{
${ }^{11}$ Excede los límites de este trabajo atender a otro aspecto que se articula con estas reflexiones: la pregunta acerca de cuál era el imaginario sobre el mito de origen que se encarna en esos objetos en las distintas épocas y lugares. Véase al respecto Bovisio y Penhos 2010.
} 
Braun, B. (1993). Pre-Columbian Art in the Post-Columbian World, en: Post-Columbian World. Ancient American Sources of Modern Art. New York: Harry N. Abrams, INC.

Buzio de Torres, C. (1991). La Escuela del Sur: la asociación e arte constructivo, 1934-42. La Escuela del Sur. El taller Torres García y su legado. Madrid: Museo Nacional Centro de Arte Reina Sofía.

Clifford, J. (1995). Dilemas de la cultura. Barcelona: Gedisa.

Cortés, H. (1963) Cartas y documentos, México: Porrúa.

Debenedetti, S. (1931). L'Ancienne Civilisation des Barreales, la Cienaga et la Aguada, d'âpres les collections privées et les documents de Benjamin Muniz Barreto. Paris: G.Van Oest.

De Xerez, F. (2003 [1534]). Verdadera relación de la conquista del Perú, disponible en: www. biblioteca.org.ar/libros/645.

Díaz del Castillo, B. (1992). Verdadera Historia de la Conquista de la Nueva España, México: Porrúa. Díaz del Castillo, B. (1992 [1568]) Historia verdadera de la conquista de la Nueva España, México: Porrúa.

Dürer, A. (1914 [1520]). Tagebuch der Reise in di Niderlande, Leipizig.

Gruzinski, S. (1994). La guerra de las imágenes. México: FCE.

Humboldt, Alexander von et Bonpland, Aimé. (1971 [1810]). Atlas pittoresque du voyage vues des cordillères, París: Theatrvm Orbis Terrarvm Ltd.

Lévi-Strauss, C. (1979). Arte, lenguaje y etnología. Entrevistas con Georges Charbonier, México: Siglo XXI [1 $1^{\text {a }}$ edición en francés 1968].

Paternosto, C. (2001). Abstracción el paradigma amerindio. Valencia: IVEM.

Aires: F.C.E.

Penhos, M. (2005). Ver, conocer, dominar. Imágenes de Sudamérica a fines del siglo XVIII. Buenos Aires: Siglo XXI.

Ramírez, M. C. (1991). La Escuela del Sur: el legado del Taller Torres García en el arte latinoamericano.

En: La Escuela del Sur. El taller Torres García y su legado. Madrid: Museo Nacional Centro de Arte Reina Sofía.

Rojas Mix, M. (1992). América imaginaria. Barcelona: Lumen.

Shelton, A. (1994). Cabinets of Transgression: Renaissance Collections and the Incorporation of the New World. En: Elsner, J. y Cardinal, R: The Cultures of Collecting. Cambridge: Harvard University Press.

Torres García, J. (2000). Historia de mi vida. Montevideo: ARCA.

(1991). Manifiesto N² 2, Montevideo, diciembre 1938. En: La Escuela del Sur.

El taller Torres García y su legado. Madrid: Museo Nacional Centro de Arte Reina Sofía.

(1939). Metafísica de la prehistoria indoamericana. Montevideo: Asociación de

Arte Constructivo. 